\title{
Minireviews
}

\section{Artificial Oxygen Carriers-Past, Present, and Future-a Review of the Most Innovative and Clinically Relevant Concepts ${ }^{\mathrm{S}}$}

\author{
Katja B. Ferenz and Andrea U. Steinbicker \\ Institute of Physiology, University Hospital Essen, University of Duisburg-Essen, Essen, Germany (K.B.F.); and Department of \\ Anesthesiology, Intensive Care and Pain Medicine, Westphalian Wilhelminian University Muenster, University Hospital Muenster, \\ Muenster, Germany (A.U.S.)
}

Received October 25, 2018; accepted February 12, 2019

\begin{abstract}
Blood transfusions are a daily practice in hospitals. Since these products are limited in availability and have various, harmful side effects, researchers have pursued the goal to develop artificial blood components for about 40 years. Development of oxygen therapeutics and stem cells are more recent goals. Medline (https://www.ncbi.nlm.nih.gov/pubmed/?holding=ideudelib), ClinicalTrials.gov (https://clinicaltrials.gov), EU Clinical Trials Register (https://www.clinicaltrialsregister.eu), and Australian New Zealand Clinical Trials Registry (http://www.anzctr.org. au) were searched up to July 2018 using search terms related to artificial blood products in order to identify new and ongoing research over the last 5 years. However, for products that are already well known and important to or relevant in gaining a better understanding of this field of research, the reader is
\end{abstract}

punctually referred to some important articles published over 5 years ago. This review includes not only clinically relevant substances such as heme-oxygenating carriers, perfluorocarbonbased oxygen carriers, stem cells, and organ conservation, but also includes interesting preclinically advanced compounds depicting the pipeline of potential new products. In- depth insights into specific benefits and limitations of each substance, including the biochemical and physiologic background are included. "Fancy" ideas such as iron-based substances, $\mathrm{O}_{2}$ microbubbles, cyclodextranes, or lugworms are also elucidated. To conclude, this systematic up-to-date review includes all actual achievements and ongoing clinical trials in the field of artificial blood products to pursue the dream of artificial oxygen carrier supply. Research is on the right track, but the task is demanding and challenging.

\section{Introduction}

Every day, thousands of patients receive red blood cell (RBC) concentrates to maintain essential functions such as oxygen delivery (Meier et al., 2016). In the recent years, state of the art methods have been developed, such as conservation of blood, anticoagulants, and safety regarding infections. Nevertheless, while blood saves life, RBC concentrate transfusions have important side effects such as immune modulations, acute transfusion reactions, transfusion-related lung injury, volume overload, and hemolytic reactions. RBC

The authors do not have funding information to disclose.
The authors declare no conflict of interest.

https://doi.org/10.1124/jpet.118.254664.

S This article has supplemental material available at jpet.aspetjournals.org. concentrates cannot be stored without obtaining side effects called the storage lesion (Brunskill et al., 2015; Tissot et al., 2017). Transfusion-associated bacterial contamination and viral infections have been reported. The incidence of cancer receding and an increase in mortality have been reported for bladder, colon, and gastric cancer (Sun et al., 2015; Velásquez and Cata, 2015; Amri et al., 2017; Furrer et al., 2018), and rare-but still occurring-mistransfusions may lead to severe problems.

To minimize the risks of RBC concentrate transfusions, patient blood management programs have enabled more careful use of blood products (Meybohm et al., 2016). Demographic changes have led to more elderly people who require surgery. Therefore, artificial oxygen carriers (AOCs) may be required to enable surgery in all patients since donated blood has also become a sparce source. The actual

ABBREVIATIONS: AOC, Artificial oxygen carrier; BAEGF-Hb, antioxidative bromoacethylethyleneglycol-ferulate-linked human hemoglobin; bPEG$\mathrm{Hb}$, bovine pegylated hemoglobin; CO, carbon monoxide; Hb-PDA, antioxidative polydopamine-coated bovine Hgb nanocapsules; HBOC, hemoglobin-based oxygen carrier; HbN, hemoglobin nanoparticles; HbP, polymer encapsulated bovine hemoglobin; Hgb, hemoglobin; LEH, liposome-encapsulated hemoglobin; $p_{50}$, partial pressure of $\mathrm{O}_{2}$ at which hemoglobin is saturated to $50 \%$; HrBOC, hemerythrin-based oxygen carriers; LOM, Lipid-based oxygen microbubbles; PDA-Hb microcapsules, polydopamine-coated bovine hemoglobin microcapsules; PEGLtEC, pegylated Lumbricus terrestris erythrocruorin; PHMs, Polymer hollow microparticles; PFC, perfluorocarbon; PFOC, perfluorocarbon-based oxygen carrier; PolyPHb, polymerized human placenta hemoglobin; RBC, red blood cell; RBCM, red blood cell-like microgel particles loaded with bovine hemoglobin; SC, stem cell. 


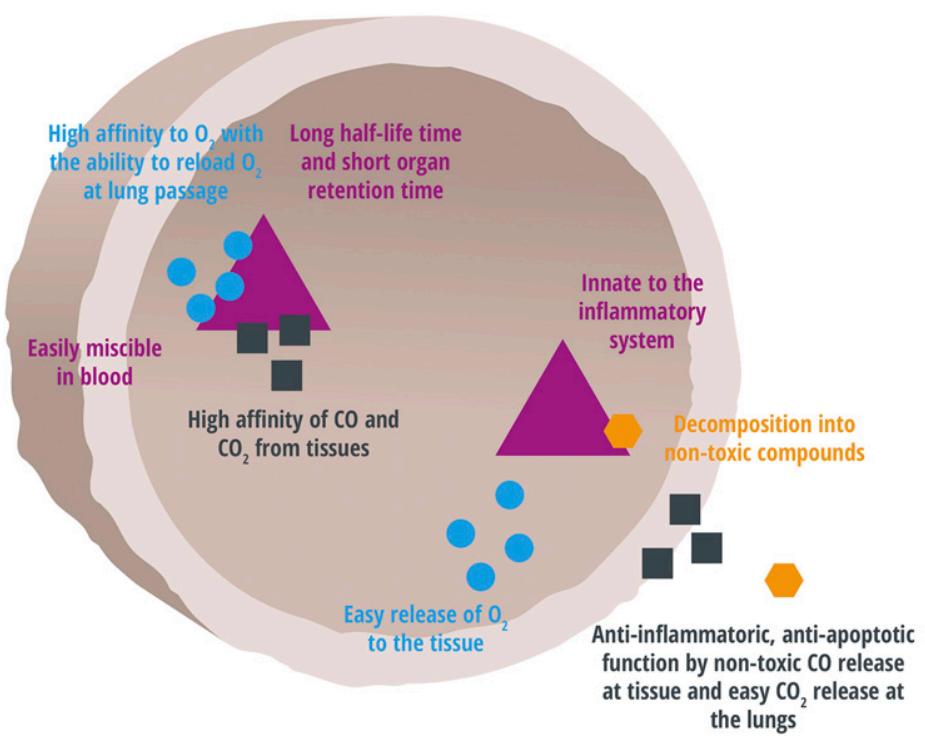

$\mathrm{O}_{2}$

$\Delta$ Artifical oxygen carrier

$\mathrm{CO}, \mathrm{CO}_{2}$

Macrophages and immune system
Fig. 1. Demands of the perfect artificial oxygen carrier. In Fig. 1, the demands of a perfect AOC are depicted. High affinity to oxygen with an easy release at the tissue is an essential objective. High affinity to $\mathrm{CO}$ and $\mathrm{CO}_{2}$ with also an easy release at the lung passage is a second required goal. The major problems of artificial components are the induction of the inflammatory reactions of the body, hypotension, and hypertension. idea in the field of AOCs has shifted during the past 40 years from blood substitution to oxygen therapeutics (Spahn, 2018). Many compounds have been developed, but the ideal, clinical useful product has not yet been developed (Simoni, 2017). The overall aim is to provide an additional tool for physicians in clinical situations, in which blood may not be available, might not be an option (such as antibodies against blood compounds or religious reasons), or oxygen delivery is required (i.e., transplantation).

An overview of the demands of a perfect AOC is given in Fig. 1. Besides high affinity to $\mathrm{O}_{2}$ with easy release at the tissue, high affinity to carbon monoxide ( $\mathrm{CO}) /$ carbon dioxide $\left(\mathrm{CO}_{2}\right)$ with easy release during the lung passage are required goals. Major problems associated with AOCs are the induction of the inflammatory reaction of the body, hypotension, and hypertension.

This review gives an overview (please see Fig. 2) about the current preclinically and clinically relevant AOCs, which include hemoglobin (Hgb)-based oxygen carriers (HBOCs), perfluorocarbon-based oxygen carriers (PFOCs), and stem cells (SCs). As shown in Fig. 2A, perfluorocarbons (PFCs)
A

PFCs<smiles>FC1(F)C(F)(F)C(F)(F)C2(F)C(F)(F)C(F)(F)C(F)(F)C(F)(F)C2(F)C1(F)F</smiles><smiles>FC(F)(F)C(F)(F)C(F)(F)C(F)(F)C(F)(F)C(F)(F)C(F)(F)C(F)(F)Br</smiles>

C

stem cells
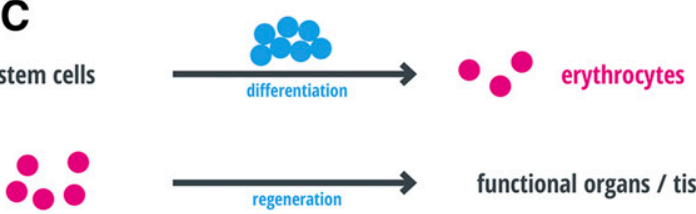

functional organs / tissue
B

HBOCs

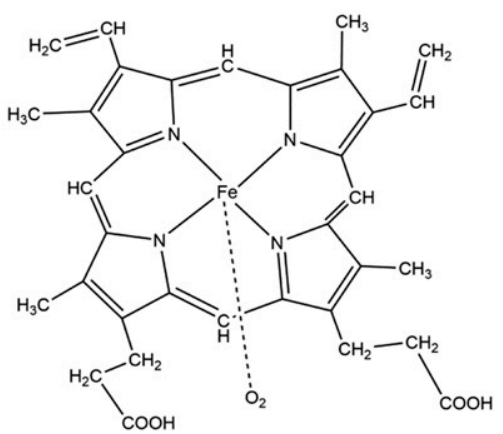

Fig. 2. Overview of different types of AOCs. To date, the following AOC categories can be described: (A) PFOCs, which are halogenesubstituted compounds; (B) HBOCs, which have a central ion atom (most frequently iron) that is oxygenated and surrounded by tetrapyrroles; (C) SCs, which can develop into different target tissues; and (D) oxygen emulsions, which are useful in increasing oxygen in liquids. Structural formula in part adapted with permission from Ferenz (2019).

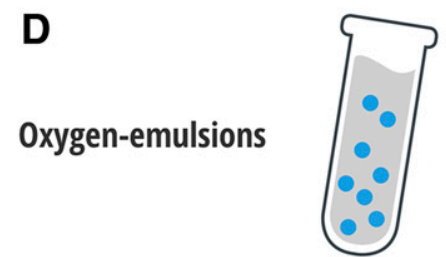


are halogene-substituted compounds, while HBOCs (Fig. 2B) have a central ion (most frequently iron) surrounded by tetrapyrroles. SCs can develop into RBC concentrates or other target tissues (Fig. 2C) and oxygen emulsions are useful in increasing oxygen in liquids (Fig. 2D). The biochemical and physiologic details of HBOCs and PFOCs are given in Tables 1 and 2, respectively. A summary of the important achievements, such as quality improvement prior to transplantation, with AOCs used for organ conservation is shown in Fig. 3.

For a variety of other substances, please see the Supplemental Material, which includes the following detailed information: recent clinical trials with Hemopure (Supplemental Table 1); clinical studies on other HBOCs (Hemolink, Polyheme, pyridoxalated hemoglobin polyoxyethylene conjugate, and Hemotech) (Supplemental Table 2); trials with hemospan/MP4OX (Sangart Inc.) and MP4CO (Sangart) (Supplemental Table 3); clinical trials with Sanguinate (Supplemental Table 4); sophistically engineered Hgbs (including OxyVita, poly-Hb-tempol, Sanflow, VitalHeme, YQ23, antioxidative bromoacethylethyleneglycolferulate-linked human hemoglobin (BAEGF-Hb), and polymerized human placenta hemoglobin $(\mathrm{PolyPHb}) /$ bovine pegylated hemoglobin (bPEG-Hb)) (Supplemental Table 5); standard Hgb plus engineered envelope (HbVesicles, HbMP-700, ErythroMer, hemoglobin nanoparticles $(\mathrm{HbN})$, polymer encapsulated bovine hemoglobin (HbP), liposome-encapsulated hemoglobin (LEH), antioxidative polydopamine-coated bovine Hgb nanocapsules (Hb-PDA), polydopamine-coated bovine hemoglobin microcapsules (PDA-Hb microcapsules), Hemoact, red blood cell-like microgel particles loaded with bovine hemoglobin (RBCM), Mal-PEG- $\beta$-xl-Hb and hemoglobin-loaded nanoliposome) (Supplemental Table 6); and other artificial blood products in preclinical stage (HemoCD, pegylated Lumbricus terrestris erythrocruorin (PEGLtEC), hemerythrin-based oxygen carriers (HrBOC), cobalt-replaced myoglobin, cobalt porphyrin-based micelles, and Lipid-based oxygen microbubbles (LOM)/Polymer hollow microparticles (PHMs)) (Supplemental Table 7). Please note, that per definition, free, unmodified hemoglobins do not belong to AOCs and have, therefore, not been included in this review.

\section{Methods}

Medline was searched up to July 23, 2018 (https://www.ncbi.nlm. nih.gov/pubmed/?holding=ideudelib). The following search terms were used: perfluorocarbon-based oxygen carriers, perfluorocarbon based oxygen carriers, hemoglobin-based oxygen carriers, hemoglobin based oxygen carriers, artificial oxygen carriers, artificial AND blood AND substitutes, organ preservation AND perfluorocarbons, organ preservation AND hemoglobin-based artificial oxygen carriers, organ preservation AND artificial oxygen carriers,

TABLE 1

HBOCs at a glance: natural Hgb from an organism

\begin{tabular}{cc}
\hline Important Parameter/Compounds & Example \\
\hline
\end{tabular}

Compounds (abandoned)

Hemolink, Polyheme, DClHb, Hemotec, rHb1.0/2.0, and Hemospan/MP4OX/MP4CO

Compounds (recently investigated)

Hemopure: life-threatening anemia if blood transfusion is not an option (in the United States) since 2013

Saguinate: emergency protocol (thus far, two patients that refused blood transfusions survived)

Hemo2life: to improve kidney quality prior to transplantation, hypothermic maschine perfusion

Compounds (recently investigated preclinically)

Misciability with blood

Origin of hemoglobin

High range of oxygen affinity $\left(p_{50}\right)$

High carbon monoxide affinity

High molecular weight/size

Metabolism

Intravascular half-life

Recent studies performed in animals

Recent studies performed in humans

Application areas other than substitution of blood in whole organism

Concerns of regulatory authorities

Current-to-future intent

Reviews elucidating biochemistry/physiology behind HBOCs
Oxyvita, HbVesicles, ErythroMer, and HemoAct

Unproblematic for all HBOCs

1) Human (blood donation required) or 2) bovine/lugworm (risk of infection such as prions)

Hemopure (38 mm Hg), Hemospan/MP4OX (6 mm Hg), and HbVesicles (9-30 mm Hg)

Some compounds are designed to deliver therapeutic, nontoxic levels of $\mathrm{CO}$ (for example, Sanguinate)

Surrounded by any type of membrane or crosslinked (crosslinking between monomers to stable tetramers as well as crosslinking of tetramers to molecules affecting oxygen affinity or size. Therefore, huge variation [for example, OxyVita $(17 \mathrm{kDa})$ and Hemo2Life $(3600 \mathrm{kDa})]$

Crosslinking agents and shell material often cause immunoreactions or may increase methemoglobin formation

$18-23 \mathrm{~h}$

Erythromer: rat hemorrhagic shock model, murine hemodilution model (70\% blood exchange)

OxyVita: preclinical studies of prehospital setting of hemorrhagic shock (Jahr JS, Akha AS, Holtby RJ (2012))

Hemopure in South Africa 2001 and Russia 2012 clinically approved

Hemo2Life in kidney transplantation for organ preservation, recently completed

HbVesicles: isolated organ perfusion, ECMO priming, and 2D cell cultures [Sakai $\mathrm{H}$

(2017), Kohno M, Ikeda T, Hashimoto R, Izumi Y, Watanabe M, Horinouchi H, Sakai H, Kobayashi K, Iwazaki M (2017)]

Hemo2life: isolated organ preservation

Reviewed in Jahr JS, Akha AS, Holtby RJ (2012), Chen J-Y, Scerbo M, Kramer G (2009) Safety issues. Problem with HBOCs: not funcional in the presence of flue gases. FDA: 2008 safety concerns for Hemopure

1) Intent to get approval for Hemopure in Europe/Germany, 2) recombinant Hgb from plants, and 3) use the more stable fetal Hgb

Cabrales and Friedman (2013), Varnado et al. (2013), Alayash (2014), Njoku et al. (2015), Taguchi et al. (2017), 
TABLE 2

PFOCs at a glance

\begin{tabular}{|c|c|}
\hline Important Parameter/Compound & Example \\
\hline Compounds (abandoned) & Fluosol-DA, Oxycyte: no more in trials since 2014 \\
\hline $\begin{array}{l}\text { Compounds (recently investigated in clinical } \\
\text { trials) }\end{array}$ & $\begin{array}{l}\text { Perftoran (Perftec): approved for human clinical use in Russia, Mexico, Kazakhstan, } \\
\text { Kyrgyzstan, and Ukraine (Castro and Briceno (2010)), e.g., resuscitation from hemorrhagic } \\
\text { shock, cardioplegia } \\
\text { Oxygent: produced, licensed, and approved for clinical studies in China (Liu (2017)), e.g., } \\
\text { patients undergoing orthopedic and non-cardiac surgery after hemodilution to hgb of } 9 \mathrm{~g} / \mathrm{dl}\end{array}$ \\
\hline $\begin{array}{l}\text { Compounds (recently investigated in } \\
\text { pre-clinical trials) }\end{array}$ & Albumin-derived perfluorodecalin-filled nanocapsules \\
\hline Misciability with blood & To provide compatibility with the aqueous medium blood, PFCs have to be emulsified or encapsulated. \\
\hline $\begin{array}{l}\text { High oxygen }\left(p_{50}\right) \text { and carbon monoxide } \\
\text { affinity }\end{array}$ & $\begin{array}{l}\text { No saturation of } \mathrm{O}_{2} \text { and } \mathrm{CO}_{2} \text { occurs, dissolubility dependent on gas partial pressure, in addition } \\
\text { to respiratory gases PFCs also dissolve } \mathrm{CO} \text { and } \mathrm{N}_{2} \text {, which are relevant in the treatment of flue- } \\
\text { gas poisonings or gas embolism and decompression sickness (Spiess BD (2009)). }\end{array}$ \\
\hline High molecular weight/size & Emulsified or encapsulated displaying a droplet size of $100-300 \mathrm{~nm}$ \\
\hline Metabolism & $\begin{array}{l}\text { Fully halogenated, mainly fluorinated, molecules. Strong carbon-fluorine bond, no toxic } \\
\text { metabolites are formed. Elimination: first, uptake into macrophages, and then diffusion into the } \\
\text { blood, association to lipoproteins, and transport to the lung, where they can be exhaled (if vapor } \\
\text { pressure is favorable, e.g., perfluorodecalin or perfluorooctylbromide) (Lowe }(2003,2006) \text { ). }\end{array}$ \\
\hline Easy release of $\mathrm{O}_{2}, \mathrm{CO}$, and $\mathrm{CO}_{2}$ & $\begin{array}{l}\text { Oxygen loading and unloading is two times faster than in erythrocytes and the oxygen } \\
\text { extraction rate is 3-fold higher since PFCs release more than } 90 \% \text { of the loaded oxygen to the } \\
\text { tissue (Faithfull NS, 1992; Keipert PE, Faithfull NS, Roth DJ, Bradley JD, Batra S, } \\
\text { Jochelson P, Flaim KE, 1996). }\end{array}$ \\
\hline Intravascular half-life & 158 min till 8 days \\
\hline $\begin{array}{l}\text { Application areas other than substitution } \\
\text { of blood in whole organism }\end{array}$ & $\begin{array}{l}\text { Used for organ preservation of islets, brain, kidney, pancreas, and heart either in static cold } \\
\text { storage or for machine perfusion (Zhang H, Barralet JE. Mimicking oxygen delivery and waste } \\
\text { removal functions of blood. Adv Drug Deliv Rev 2017), reviewed in Hosgood SA, Nicholson ML. } \\
\text { The role of perfluorocarbon in organ preservation. Transplantation 2010;89: 1169-75. }\end{array}$ \\
\hline Recent studies performed in animals & $\begin{array}{l}\text { Albumin-derived perfluorodecalin-filled nanocapsules showed promising results in a first } \\
\text { in vivo toxicity study (Wrobeln A, Laudien J, Gross-Heitfeld C, Linders J, Mayer C, Wilde B, } \\
\text { Knoll T, Naglav D, Kirsch M and Ferenz KB (2017a)) and protected a Langendorff heart (rat) } \\
\text { during massive ischemia Wrobeln A, Schluter KD, Linders J, Zahres M, Mayer C, Kirsch M } \\
\text { and Ferenz KB (2017b). }\end{array}$ \\
\hline Studies performed in humans & $\begin{array}{l}\text { Oxycyte: phase II completion in } 2008 \text { in patients with traumatic brain injury (Fabian TC. } \\
\text { Perfluorocarbons. J Trauma 2011;70: S42-4.), phase II study on safety and efficacy in } \\
2009 \text { was terminated by the sponsor in } 2014 \text {. }\end{array}$ \\
\hline Concerns of regulatory authorities & $\begin{array}{l}\text { Lack of patient enrollment for clinical studies (Therapeutics T. Oxygen Biotherapeutics } \\
\text { Announces Halt of Oxycyte Phase IIb Traumatic Brain Injury Trial. Morrisville, N.C.: Tenax } \\
\text { Therapeutics, 2014) long organ retention times (Riess, 2001, 2005). }\end{array}$ \\
\hline Current-to-future intent & $\begin{array}{l}\text { 1) Introduce Perftoran (Perftec) as Vidaphor to the markets in the United States and Europe; } \\
\text { 2) resume development of Oxygent in China }\end{array}$ \\
\hline $\begin{array}{l}\text { Reviews elucidating biochemistry/physiology } \\
\text { behind PFOCs }\end{array}$ & $\begin{array}{l}\text { Cabrales and Intaglietta, ASAIO J. 2013; 59(4): 337-354. DOI:10.1097/MAT.0b013e318291fbaa., } \\
\text { Riess }(2001,2005)\end{array}$ \\
\hline
\end{tabular}

normothermic perfusion AND artificial oxygen carriers, normothermic perfusion AND perfluorocarbons, organ perfusion AND artificial oxygen carriers organ perfusion AND perfluorocarbons, natural extracellular hemoglobin, and stem cells AND oxygen carriers.

Furthermore, trial registers of the United States, Europe, and Australia [ClinicalTrials.gov (https://clinicaltrials.gov), EU Clinical Trials Register (https://www.clinicaltrialsregister.eu/), and Australian New Zealand Clinical Trials Registry (http://anzctr.org.au)] were searched up to July 23, 2018, using the drug names DCLHb, ErythroMer, Hbmp-700, Hemopure, Hb-201, Hemoxycarrier, Hemo2life, HEMOXCell, Hemolink, Oxyvita, OxyVita Hb, Vitalheme, polynitroxylated AND pegylated AND hemoglobin, HbVesicles, Hemoact, Hemotech, HemAssist, Polyheme, pyridoxalated hemoglobin polyoxyethylene conjugate, Hemospan, MP4OX, MP4CO, Sanguinate, Oxygent, and Oxycyte. In order to introduce the reader into the context of artificial blood products, point out milestones, and explain typical problems and side effects associated with each class of substances important and relevant key articles are cited.

\section{Development of Artificial Blood Products}

The development of blood transfusions started decades ago: In 1667 blood was transfused from a dog to a human
(Roux et al., 2007), and in 1692 from lambs to humans. On September 1, 1818, the first blood transfusion from human to human was performed by Blundell (1818). However, only with the discovery of the ABO blood type by Landsteiner and Decastello survival improved (Greenwalt, 2005).

In parallel, the development of AOCs started with the aim of 1) eliminating whole blood-associated side effects and 2) providing unrestricted disposal of blood, or at least parts of it (erythrocytes). Unfortunately, the pioneering work performed in the 1930s using free Hgb extracted from human blood (Amberson et al., 1933) resulted in undesirable side effects, e.g., nephrotoxicity (Chang, 1988; Elmer et al., 2012; Cardenas et al., 2017). Twenty-seven years later, the first description of AOCs in the strict sense, namely, nano-bio-technologically engineered Hgb and other synthetic compounds surrounded by an artificial membrane or otherwise chemically engineered Hgb, evolved (Chang, 2012). Until now, three classes of AOCs have been defined:

- HBOCs;

- PFOCs; and

- AOCs derived from SCs. 

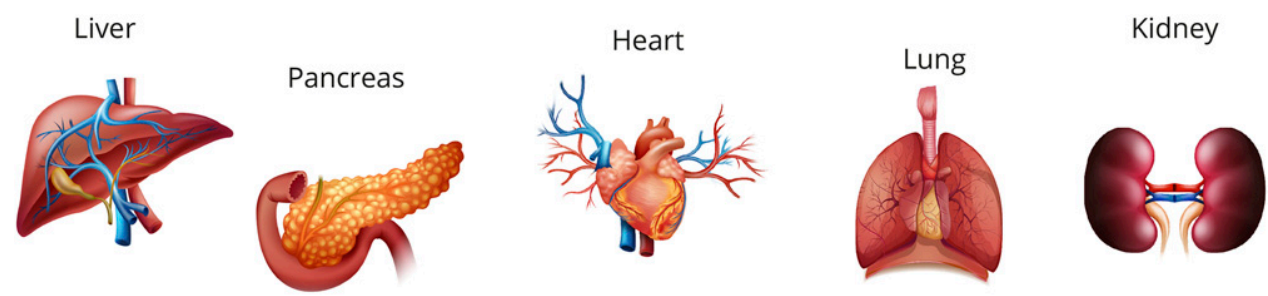

- Use of AOCs allows for normothermic perfusion without RBCs

- Retention of AOCs or metabolites not as important as in blood substitutes, AOCs mainly washed out prior to transplantation

$\downarrow$

Organ regeneration and quality improvement prior to transplantation
Kidney

Fig. 3. Organ preservation with AOCs. In organ transplantation, the major goal of AOCs is organ retention and quality improvement prior to transplantation. The use of AOCs allows for normothermic perfusion without RBC concentrates. Retention of AOCs or metabolites is not as important as in blood substitutes since AOCs are mainly washed out prior to transplantation.
The foci of this review are new preclinical and clinical developments within the last 5 years.

\section{General Requirements of Artificial Blood Products}

Clinicians and researchers have physiologic, biochemical, and technical demands on the perfect artificial blood product (Fig. 1). Of course, supplying tissue with $\mathrm{O}_{2}$ in combination with evacuation of $\mathrm{CO}_{2}$ from the periphery are the most important ones (Fig. 1). The partial pressure of $\mathrm{O}_{2}$ at which $\mathrm{Hgb}$ is saturated to $50 \%$ is given by the $p_{50}$ value. In a healthy adult, $26.6 \mathrm{~mm} \mathrm{Hg}(3.5 \mathrm{kPa})$ is normal. If the $p_{50}$ value is higher, the affinity to $\mathrm{O}_{2}$ decreases, and the standard curve shifts rightwards. A lower $p_{50}$ value indicates higher affinity to $\mathrm{O}_{2}$ with a left shift of the $\mathrm{O}_{2}$ affinity curve. The $p_{50}$ values are listed in the text and Table 1.

\section{Classes of AOCs}

\section{HBOCs: Specifications, Peculiarities, and Limitations}

HBOCs are compounds consisting of natural Hgb from different organisms (Table 1). HBOCs are attractive AOCs since they are able to deliver $\mathrm{O}_{2}$ to the tissue without an increased inspiratory $\mathrm{O}_{2}$ concentration.

The half-life of 18-23 hours is much shorter than the halflife of erythrocytes, which is 120 days; therefore, repetitive doses of $\mathrm{HBOCs}$ would be required to maintain $\mathrm{O}_{2}$ delivery for days (which was the original reason for the development of HBOCs as blood substitutes). More recently, HBOCs have been designed to bridge patients safely in clinics in order to gain time until a RBC concentrate transfusion is available. In the presence of flue gases, they do not remain functional since $\mathrm{CN}^{-}$or $\mathrm{CO}$ displaces $\mathrm{O}_{2}$ from its binding sites in the $\mathrm{Hgb}$ molecule, and additionally components of flue gas oxidize $\mathrm{Hgb}$ into methemoglobin (Met-Hgb).

HBOCs always require natural Hgb, either from outdated human RBC concentrates, extracted from animal blood or bacteria/yeast/plants. Therefore, the availability of HBOCs is still dependent on people's willingness to donate blood and the risk of infections remains (e.g., prions). In contrast, disposability of bovine blood is nearly unlimited. Instead of using Escherichia coli or Saccharomyces cerevisiae, there are now efforts to obtain recombinant Hgb (Varnado et al., 2013) from plants, e.g., from Nicotiana benthamiana (Eriksson and Bülow, 2017), and furthermore researchers are focusing more and more an fetal Hgb, which is more stable than adult Hgb (Ratanasopa et al., 2016; Simons et al., 2018). Free, unprocessed mammal Hgb that is not encased with any type of membrane is associated with typical problems (Table 3) (Cardenas et al., 2017). Encasing in any type of membrane by crosslinking between monomers (to obtain stable tetramers) as well as tetramers (to affect $\mathrm{O}_{2}$ affinity or size) (Centis and Vermette, 2009), can reduce these side effects. Furthermore increasing knowledge on the

TABLE 3

Typical side effects of unprocessed mammal Hgb

Problem

Dissociation into dimers (Chang, 1988; Elmer et al., 2012)

Nitric oxide (NO) stealing property mainly from the endothelial cell layer (Doherty et al., 1998; Olson et al., 2004; Cabrales and Friedman, 2013; Alayash, 2014)

Local hyperoxia due to decreased oxygen affinity (no diffusion barrier existent) (McCarthy et al., 2001; Alayash, 2014)

Auto-oxidation (Buehler et al., 2010; Scurtu et al., 2013; Alayash, 2014)

\section{Complication}

- Overloading the renal tubular cells (renal failure)

- Systemic and pulmonary vasoconstriction (myocardial damage pulmonary hypertension)

- Lack of mediator of thrombocyte aggregation and adhesion (impaired clotting)

- Gastrointestinal side effects

- Systemic hypertension

- Nonfunctional hemoglobin

- Formation of superoxide ions

- Altering transcriptional activity of heme oxygenase and other antioxidant enzymes 
influence of the size and surrounding shell on the pharmacokinetic properties has helped to decrease side effects (Taguchi et al., 2017). Of note, crosslinking agents and shell material may also cause immunoreactions or increase Met-Hgb formation (Centis and Vermette, 2009).

The novel lugworm Hgb lacks the typical side effects of immunoreaction and inflammation (Rousselot et al., 2006). Other relevant worms are oligochaetes (e.g., earthworms) containing erythrocruorin (Jani et al., 2017; Zimmerman et al., 2017) or worm-like animals such as sipunculans containing hemerythrin (Toma et al., 2018). Erythrocruorin contains 144 globin chains and heme-molecules. The mechanism of oxygen binding is the same as in mammal $\mathrm{Hgb}$ (formation of a dioxygen complex). Hemerythrin that does not contain any heme group forms hydroperoxides. HBOC compounds recently under clinical investigation (up to 2017) are reviewed in Njoku et al. (2015) and Gupta (2017).

Hemopure. Hemopure is glutaraldehyde-polymerized bovine Hgb. It has a molecular weight of $250 \mathrm{kDa}$ and a $p_{50}$ value of $38 \mathrm{~mm} \mathrm{Hg}$ (Jahr et al., 2008). The Food and Drug Administration terminated clinical trials in 2008 because of safety concerns (Keipert, 2017). Nevertheless, many phase I-III studies have been performed with Hemopure (Van Hemelrijck et al., 2014; reviewed in Chen et al., 2009; Jahr et al., 2012), but are no longer listed in the clinical trials registry. In other countries, clinical studies have been completed or are ongoing (Supplemental Table 1). Despite the safety concerns, the substance was clinically approved in South Africa in 2001 (Hemopure, 2014; Mer et al., 2016) and Russia in 2012 (Ortiz et al., 2014), and it has been provided to patients with life-threatening anemia in the United States for whom allogeneic blood transfusion was not an option (studies NCT01881503, NCT02684474, and NCT02934282) since 2013 (Lundy et al., 2014; Posluszny and Napolitano, 2014, 2016; Epperla et al., 2016; Resar et al., 2016; Gomez et al., 2017; Davis et al., 2018; Olaussen et al., 2018).

The basis for suspending clinical trials [see the metaanalysis by Natanson et al. (2008)] has been subsequently questioned and reevaluated by many researchers, revealing many methodological flaws and basically pointing out that there is no evidence of any NO-related toxic class effect applicable for every HBOC (Mackenzie et al., 2015, 2017; Dubé et al., 2017). However, Hemopure-induced vasoconstriction is undisputed, and meanwhile the underlying mechanisms (NO scavenging and upregulated endothelin production) have been elucidated (Cabrales and Friedman, 2013; Taverne et al., 2017).

Other HBOCs such as Hemolink or Polyheme have been developed for indications similar to Hemopure (Supplemental Table 2) (Jahr et al., 2012). To date, none of these therapeutic products has entered the clinics due to increased 30-day mortality, hypertension, and myocardial infarction (Njoku et al., 2015).

Hemospan/MP4OX. Hemospan is human Hgb conjugated with maleimide-poly (ethylene)glycol. It has a molecular weight of $96 \mathrm{kDa}$ and a $p_{50}$ value of $6 \mathrm{~mm} \mathrm{Hg}$ (Winslow, 2006). Its Hgb content of $4.2 \mathrm{~g} / \mathrm{dl}$ is too low to solely supply an organism with oxygen. Therefore, Hemospan, later named MP4OX, was developed as an $\mathrm{O}_{2}$ therapeutic to improve the oxygen supply rather than to fully replace blood (Jahr et al., 2012). Injection of MP4OX caused a low antioxidant response and a tendency to extravasation into tissue in a rat model
(Terraneo et al., 2017). In recent years, MP4OX was refined as a therapeutic treatment for special occasions such as in the treatment of sickle cell anemia. CO prevents and reverses polymerization of hemoglobin-S and thus distortion of sickled erythrocytes (Keipert et al., 2016). By using MP4OX, the pain, severity, and duration of a sickle cell anemia crisis can be reduced. Additionally, low-dose CO also acts as a signaling molecule to reduce inflammation and $\mathrm{O}_{2}$ requirement as well as to prevent apoptosis in patients (Keipert et al., 2016). The scientific and medical underlying mechanisms have been studied. MP4OX leads to induction of nuclear factor-erythroid 2 p45-related factor- 2 and hepatic hemeoxygenase- 1 as well as inhibition of the nuclear factor kappa-light-chain enhancer of activated B-cells observed in an animal model (Belcher et al., 2013), and has been reviewed in Simoni (2017). After unloading $\mathrm{CO}$, the compound is oxygenated in the lung and thereby transforms into MP4OX. The effects of MP4OX have been further investigated in animal models of sickle cell anemia (Tsai et al., 2015). Relevant clinical trials with Hemospan/ MP4OX and MP4CO are listed in Supplemental Table 3. A retrospective phase II b study (NCT01262196) was criticized, since the authors reported a numerically higher percentage of patients treated with MP4OX were alive and discharged from hospital at day 28 (primary efficacy endpoint) versus controls (57\% vs. $50 \% P=0.18$ ) (Keipert, 2017), although the study was underpowered (Keipert, 2017).

Sanguinate. Sanguinate is bovine Hgb crosslinked to poly(ethylene)glycol to enlarge the molecule and hide it from the immune system. It has a molecular weight of $120 \mathrm{kDa}$ and a $p_{50}$ value of $7-16 \mathrm{~mm} \mathrm{Hg}$ (Abuchowski, 2016). Sanguinate releases $\mathrm{CO}$ to provide antiapoptotic and anti-inflammatory properties (see MP4CO); CO additionally reduces auto-oxidation of Hgb (Abuchowski, 201). Clinical trials with Sanguinate are listed in Supplemental Table 4. Sanguinate is available under an emergency investigational new drug protocol. Thus far, it has enabled survival of only a few patients refusing transfusion due to religious reasons (Posluszny and Napolitano, 2014; Abuchowski, 2016; Resar et al., 2016).

Hemo2life. Hemo2life is Hgb extracted from lugworms, which is not packed into erythrocytes or any other membrane. It has a molecular weight of $3600 \mathrm{kDa}$ and a $p_{50}$ value of $7 \mathrm{~mm} \mathrm{Hg}$ (Mallet et al., 2014). One molecule transports up to 156 molecules of $\mathrm{O}_{2}$, which is $38 \times$ more than mammal Hgb. Hemo2life has natural superoxide-dismutase-like activity that compensates for oxygen-related radicals (Mallet et al., 2014). A clinical phase I open label trial in kidney transplantation [cold storage in Belzer (University of Wisconsin) versus hypothermic machine perfusion with Belzer (University of Wisconsin) + Hemo2life before transplantation] was completed in February 2018 (NCT02652520). Furthermore, Hemo2life improved static storage of donor hearts prior to transplantation in a preclinical animal model (Teh et al., 2017) and early graft function after hypothermic static preservation after prolonged cold ischemia of a pig lung (Glorion et al., 2018).

\section{In the Pipeline/Preclinical Development}

Many new research approaches have evolved within the last few years, all of which still are in preclinical status. The four most advanced compounds are OxyVita, HbVesicles, ErythroMer, and HemoAct. 
OxyVita (OxyVitaHb). OxyVita is bovine Hgb that is inter- and intramolecularly crosslinked, leading to a homogenous globular-like molecule. It has a molecular weight of $17 \mathrm{kDa}$. OxyVita has two subtypes: OxyVita $\mathrm{Hb}$ and OxyVita HbCO (Wollocko et al., 2017). Importantly, the Hgb tetramers are linked to each other via amide bonds without any linker molecule (Wollocko et al., 2017). Normally, toxic linker molecules such as glutaraldehyde are necessary for these linking reactions.

The release of free heme-iron into the circulation is low so that toxic side effects are minimized (Wollocko et al., 2017). OxyVita was tested in different preclinical studies, among them a pre-hospital setting (mimicking initial medical treatment of severely injured patients prior to hospital) of hemorrhagic shock in rats (Jahr et al., 2012). No other HBOC developed thus far has provided success in a battle-field model of severe hemorrhage (Jahr et al., 2012).

HbVesicles. HbVesicles are human Hgb encapsulated by a biocompatible liposome (Azuma et al., 2017). They are 250-280 $\mathrm{nm}$ in diameter, decorated with $\mathrm{PEG}_{5000}$ and have a $p_{50}$ value between 9 and $30 \mathrm{~mm} \mathrm{Hg}$ that is adjusted with pyridoxalphosphate (Sakai, 2017). Depending on the Hgb core

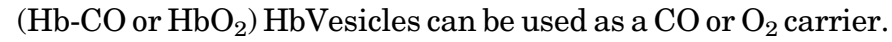
$\mathrm{HbVesicles}$ do not contribute to the colloid osmotic pressure. HbVesicles have been studied in preclinical animal blood exchange and hemorrhagic shock models and were also tested in different areas such as isolated organ perfusion, extracorporeal membrane oxygenation priming, apnoe and two-dimensional cell cultures (Kohno et al., 2017; Sakai, 2017).

ErythroMer. ErythroMer is human Hgb surrounded by a NO-attenuating polymer shell. It contains antioxidants (leukomethyleneblue) + a pH-sensitive 2,3-bisphosphoglycerate shuttle, resulting in $\mathrm{pH}$-sensitive $\mathrm{O}_{2}$ affinity. Thus far, ErythroMer has been studied in a murine hemodilution model of $70 \%$ blood exchange and a rat hemorrhagic shock model (Pan et al., 2016; ErythroMer, 2017).

HemoAct. HemoAct is a cluster of human Hgb covalently wrapped by a defined amount of human albumin molecules (mainly 3, Hb- $\mathrm{HSA}_{3}$ ) (Haruki et al., 2015). The intravascular half-life of HemoAct is 18.5 hours. HemoAct has been well tolerated; only a transient increase in mean arterial pressure was observed in controls as well as in HemoAct-treated rats, and 7 days later no organ damage was detected. HemoAct accumulated mainly in the liver as expected from its structure (Haruki et al., 2015). Other interesting approaches consist of either sophistically engineered Hgb (Supplemental Table 5) or standard Hgb in a sophisticated envelope (Supplemental Table 6); these products are all in the early preclinical stage.

\section{PFOCs: Specifications, Peculiarities, and Limitations}

Perfluorocarbons are fully halogenated, mainly fluorinated, molecules. Because of the strength of the carbonfluorine bond, no toxic metabolites in the body are formed (Riess, 2001). Compared with water, PFCs exhibit high solubility of respiratory gases that linearly depend on their partial pressure. In contrast to $\mathrm{Hgb}$, no saturation of $\mathrm{O}_{2}$ and $\mathrm{CO}_{2}$ occurs. $\mathrm{O}_{2}$ loading and unloading is two times faster than in erythrocytes and the $\mathrm{O}_{2}$ extraction rate is 3 -fold higher since PFCs release more than $90 \%$ of the loaded $\mathrm{O}_{2}$ to the tissue (Faithfull, 1992; Keipert et al., 1996).

In addition to respiratory gases $\mathrm{PFCs}$ also dissolve $\mathrm{CO}$ and $\mathrm{N}_{2}$, which is relevant in the treatment of flue-gas poisonings or gas embolism/decompression sickness (Spiess, 2009). Typical side effects of PFOCs are a decrease in the mean arterial pressure, lung damage, thrombocytopenia, and flue-like symptoms, in addition to poor emulsion stability and long organ retention time (Lowe, 2003; Hosgood and Nicholson, 2010). To provide compatibility with the aqueous medium blood, PFCs have to be emulsified or encapsulated for use as AOCs. Such emulsions normally display a droplet size of 100-300 nm, but are highly sensitive to flocculence and Oswald ripening when not stored frozen. Toxic emulsifiers such as Pluronic-F68 improve the stability of the formulation, but are one of the factors responsible for side effects such as transient hypotension, immunoreaction, and activation of the complement system (Kuznetsova, 2003).

In newer formulations biocompatible emulsifiers such as egg yolk phospholipids or high molecular weight PFCs are used, e.g., perfluorotributylamine or perfluoromethylcyclohexylpiperidine (however, these are associated with long organ retention times) (Riess, 2005). After uptake of the emulsion droplets into macrophages, PFCs such as perfluorodecalin or perfluorooctylbromide (possessing appropriate vapor pressure) diffuse back into the blood and are associated with lipoproteins transported to the lung where they can be exhaled (Lowe, 2006).

Actually, there is only one PFOC, Perftoran (Perftec) that has been approved for human clinical use in Russia, Mexico, Kazakhstan, Kyrgyzstan, and Ukraine (Castro and Briceno, 2010). Perftoran is now produced under standard manufacturing practice (brand name Vidaphor) with the aim of introducing it to markets in the United States and Europe (Latson, 2017; Vidaphor, 2017).

PFOCs were also used in the context of organ preservation such as in brain, kidney, pancreas, liver (Okumura et al., 2017), and heart either in static cold storage or for machine perfusion (Zhang and Barralet, 2017), an overview is given in (Hosgood and Nicholson (2010). The use of PFOCs allows for $\mathrm{RBC}$ concentrate-free normothermic perfusion, and thus for organ regeneration prior to transplantation (Fig. 3).

\section{Compounds under Clinical Investigation}

Currently there is only one compound that has been investigated in clinical trials: Oxygent. Oxygent is a $60 \% \mathrm{PFC}$ emulsion (58\% perfluorooctylbromide, $2 \%$ perfluorodecylbromide and egg-yolk phospholipids). Oxygent has been known since the 1990s and has been studied in several clinical studies (Castro and Briceno, 2010; Spahn and Keipert, 2017). Among these studies, especially in two phase III studies, the potential of Oxygent was successfully shown. The first study investigated patients undergoing orthopedic surgery, who were preoperatively normovolemic hemodiluted with colloid to a target $\mathrm{Hgb}$ of $9 \mathrm{~g} / \mathrm{dl}$. The normovolemic hemodilution was followed by either treatment with Oxygent, autologous blood, or conventional colloid when reaching a predefined transfusion trigger. Patients in the Oxygent group showed the longest duration of transfusion-trigger reversal, thus Oxygent was more effective than blood or colloid in stabilizing the patients and avoiding additional transfusions (Spahn et al., 1999). These results were 
confirmed in a second clinical trial in patients undergoing noncardiac surgery. Preoperative hemodilution was followed by two doses of Oxygent. Oxygent reduced the need for blood transfusions compared with the standard care (no hemodilution; intraoperative transfusion of $\mathrm{RBC}$ concentrates if indicated) (Spahn et al., 2002).

However, in 2002, Oxygent was abandoned because of safety issues in a phase III coronary artery bypass grafting trial (Keipert, 2006). In 2017, Oxygent was reproduced by Double Chrane, licensed and approved for clinical studies in China (J. Liu, personal communication).

With the promising PFOC Oxycyte a successful phase II study was completed in 2008 in patients with traumatic brain injury (NCT00174980) (Fabian, 2011)). Another phase II study on safety and efficacy of Oxycyte was started in 2009 (NCT00908063), but was terminated by the sponsor in 2014 due to lack of patient enrollment (Oxygen Biotherapeutics Announces Halt of Oxycyte Phase IIb Traumatic Brain Injury Trial, 2014). The sponsor abandoned the substance.

\section{In the Pipeline/Preclinical Development}

Albumin-derived perfluorodecalin-filled nanocapsules showed promising results in a first in vivo toxicity study (Wrobeln et al., 2017a) and protected a Langendorff heart (rat) during massive ischemia (Wrobeln et al., 2017b). Similarly, a novel PFC emulsion increased myocardial $\mathrm{O}_{2}$ delivery, improved cardiac function, and generated a more physiologic redox state in a Langendorff heart (rabbit) compared with perfusion without the PFC emulsion (Kuzmiak-Glancy et al., 2018).

\section{Other Products}

Besides engineering $\mathrm{Hgb}$ or the surrounding shell, there are other ideas such as simply using the $\mathrm{O}_{2}$ binding porphyrin structure of Hgb [e.g., embedded in cyclodextranes (HemoCD)] (Kitagishi et al., 2017) or completely using other materials such as cobalt porphyrins (where the central iron ion in the $\mathrm{O}_{2}$-binding structure of $\mathrm{Hgb}$ is replaced by cobalt) (Neya et al., 2014; Shen et al., 2016). Furthermore, there have been attempts to directly introduce $\mathrm{O}_{2}$ into particles, thus for the first time permitting for a safe and effective intravenous injection of $\mathrm{O}_{2}$ gas, which locally increases $\mathrm{pO}_{2}$ very rapidly (Seekell et al., 2016; Black et al., 2017). All of these substances (Supplemental Table 7) are still in the preclinical stage.

\section{SCs: Specifications, Peculiarities, and Limitations}

In 2006, a new cell source, which was able to differentiate into all cell types of the endo-, ecto-, or mesodermal lineages, was found by Takahashi and Yamanaka (2006). Induced pluripotent SCs can be generated from different somatic cell sources by overexpression of specific transcription factors, e.g., HOXB4 (Takahashi and Yamanaka, 2006; Schiedlmeier et al., 2007; Yu et al., 2007). There are two approaches to using SCs within the context of AOCs (see Fig. 2C): 1) differentiation of SCs into RBC concentrates, and 2) differentiation of SCs into various target cells in an oxygenated environment. These two approaches will be described in the following sections.

Differentiation of SCs into RBC Concentrates. The major challenges to using SCs are the low retention and engraftment of transplanted cells and the adverse effects of inflammation and immunoreactions when allogeneic or xenogeneic cells are used (Van Veen and Hunt, 2015). Giarratana et al. (2011) elucidated the quality of donated hematopoietic SCs from human donors that were developed in culture into RBC concentrates in a proof-of-concept study. The difficulty was not only the viability and cell deformability, but the requirement of an improved production protocol of cultured $\mathrm{RBC}$ concentrates without feeder cells at reasonable costs (Giarratana et al., 2013). To provide the required huge amount of RBC concentrates, upscaling has to be improved. In addition, artificial RBC generation has to result in nucleus-free erythrocytes that contain only adult $\mathrm{Hgb}$ and no fetal Hgb. An advantage of this technique is that cells can be produced in a patient-specific manner according to the blood phenotype of the recipient.

Differentiation of SCs into Various Target Cells in an Oxygenated Environment. To improve SC differentiation the $\mathrm{O}_{2}$ supply to hypoxic areas should be high and the $\mathrm{O}_{2}$ gradient formation should be reduced. The differentiation potential and cell viability should be preserved and the extracellular matrix microenvironment should be kept intact. Oxidative stress and the generation of reactive oxygen species are not desired, since hematopoetic SCs might die (Jung and Choi, 2014). Therefore, the support of AOCs in SC exploitation displays an ideal combination.

Le Pape et al. (2017) evaluated the ability of HEMOXCell, a $\mathrm{HBOC}$, to carry $\mathrm{O}_{2}$ in culturing human bone marrow mesenchymal SCs in vitro for three-dimensional culture applications in human platelet lysate-supplemented media. HEMOXCell provoked a cell growth rate induction of $25 \%$, while the mesenchymal SC phentoype was preserved and typical differentiation properties were maintained. In a subsequent study, Le Pape et al. (2018) developed a perfusion culture method to provide a similar distribution of nutrient and $\mathrm{O}_{2}$ throughout the artificially engineered tissue, specifically for the setting of osseointegration in dental implant surgery. HEMOXCell was beneficial in the development of mesenchymal stem cells into allogenic bone substitute (Le Pape et al., 2018).

Similar effects were observed using the PFOC Fluosol-DA. The slopes of the single-dose radiation survival curves for intestinal epithelial cells and spermatogenic SCs in mice breathing air or $\mathrm{O}_{2}$ were not significantly altered by the administration of Fluosol-DA 10 minutes before irradiation, and the doses to achieve an isoeffect were altered by 1.03 or less. When mice were challenged with intravenously injected Fluosol-DA tumor cells, 24 hours after treatment with Fluosol-DA no increase in the number of artificial pulmonary metastases was observed (Mason et al., 1985).

Furthermore, Tang et al. (2017) created an oxygenated environment using a nanogel structure: they encapsulated human cardiac SCs in thermosensitive poly( $N$-isopropylacrylamineco-acrylic acid) nanogel in murine and pig models of myocardial infarction. In contrast to conventional SCs, encapsulated human cardiac SCs did not induce an inflammatory reaction or T-cell infiltration in immunocompetent mice, whereas xenogeneic human cardiac SCs injected in saline induced the immune response. The cardiac function was maintained and the scar sizes were reduced. The authors concluded that "thermosensitive nanogels can be used as a carrier: the porous and convoluted inner structure allows nutrient, $\mathrm{O}_{2}$ and secretion diffusion, but can prevent SCs from being attacked by immune cells" (Tang et al., 2017). 
A recent publication by Cantaluppi et al. (2018) reported that the addition of PFCs to viable renal tubular epithelial cells in a renal-assist device led to the differentiation of those cells toward renal progenitor cells.

\section{Discussion: Outlook-the Future of AOCs}

Looking at the research studies conducted over the years, it can be seen that many improvements have been made in the development of AOCs (HBOCs, PFOCs, and SCs). However, these studies have also revealed the major challenges in relation to inflammatory reactions, conservation, and $\mathrm{O}_{2}$ affinity that have to be managed in order to fully provide a clinically useful AOC. Economic aspects have often played a role and may have caused a delay or even stopped the further development of initially successful compounds. Recently, the safety profile of the HBOC Hemopure was reevaluated since new, very promising HBOCs such as Sanguinate and Hemo2life have emerged from laboratories. Furthermore, the biochemical and physiologic properties of different HBOCs have been compared in a recent study by the US Food and Drug Administration in order to facilitate the development of novel AOCs (Meng et al., 2018). Additionally, clinical studies with the PFOC Oxygent were resumed in 2017. Finally, the efforts to make the established PFOC Perftoran (Vidaphor) available in the United States and European markets may bring us closer to clinically useful AOCs.

Severely anemic patients refusing transfusion on religious grounds can benefit from AOCs. However, to date, there are just single case reports and not enough evidence to generally advise their use in combination with standard care (McConachie et al., 2018). To this end, some products have reached clinical use in selected countries. In Germany and the United States, no products have reached broad clinical use.

It is evident that research will continue since AOCs are urgently needed to meet the demands of the aging population. Blood substitution as well as oxygen therapeutics and stem cell derivatives will be the focus of research activities. It is most likely that in Europe and the United States AOCs will be used first for ex situ organ preservation prior to use as a RBC concentrate equivalent. Additionally, the artificial generation of personalized RBC concentrates from adult SCs will probably be one major path forward - especially if production of high amounts at low cost under good clinical practice conditions can be realized. The past 40 years of research have shown us that the development of AOCs is challenging. Many substances have been tested, but were not useful. Many projects were started, but failed. Nevertheless, the recent, novel developments indicate promising results to be expected within a sufficient period of time.

\section{Acknowledgments}

We thank M. Kirsch, University Duisburg-Essen, for helpful discussions on the topic.

\section{Authorship Contributions}

Participated in research design: Ferenz.

Performed data analysis: Ferenz, Steinbicker.

Wrote or contributed to the writing of the manuscript: Ferenz, Steinbicker.

\section{References}

Abuchowski A (2016) PEGylated bovine carboxyhemoglobin (SANGUINATE ${ }^{\mathrm{TM}}$ ): results of clinical safety testing and use in patients, in Oxygen Transport to Tissue XXXVII: Advances in Experimental Medicine and Biology (Elwell CE, Leung TS, and Harrison DK eds) pp 461-467, Springer, New York.

Alayash AI (2014) Blood substitutes: why haven't we been more successful? Trends Biotechnol 32:177-185.

Amberson WR, Mulder AG, Steggerda FR, Flexner J, and Pankratz DS (1933) Mammalian life without red blood corpuscles. Science 78:106-107.

Amri R, Dinaux AM, Leijssen LGJ, Kunitake H, Bordeianou LG, and Berger DL (2017) Do packed red blood cell transfusions really worsen oncologic outcomes in colon cancer? Surgery 162:586-591.

Azuma H, Fujihara M, and Sakai H (2017) Biocompatibility of HbV: liposomeencapsulated hemoglobin molecules-liposome effects on immune function. J Funct Biomater 8:E24.

Belcher JD, Young M, Chen C, Nguyen J, Burhop K, Tran P, and Vercellotti GM (2013) MP4CO, a pegylated hemoglobin saturated with carbon monoxide, is a modulator of HO-1, inflammation, and vaso-occlusion in transgenic sickle mice. Blood 122:2757-2764.

Black KJ, Lock AT, Thomson LM, Cole AR, Tang X, Polizzotti BD, and Kheir JN (2017) Hemodynamic effects of lipid-based oxygen microbubbles via rapid intravenous injection in rodents. Pharm Res 34:2156-2162.

Blundell J (1818) Observations on Transfusion of Blood. First blood transfusion from human to human: 01.09.1818. The Lancet. 1828/1829, 321.

Brunskill SJ, Wilkinson KL, Doree C, Trivella M, and Stanworth S (2015) Transfusion of fresher versus older red blood cells for all conditions. Cochrane Database Syst Rev 15:CD010801.

Buehler PW, D’Agnillo F, and Schaer DJ (2010) Hemoglobin-based oxygen carriers: from mechanisms of toxicity and clearance to rational drug design. Trends Mol Med 16:447-457.

Cabrales P and Friedman JM (2013) HBOC vasoactivity: interplay between nitric oxide scavenging and capacity to generate bioactive nitric oxide species. Antioxid Redox Signal 18:2284-2297.

Cantaluppi V, Medica D, Quercia AD, Dellepiane S, Figliolini F, Virzì GM, Brocca A, Quaglia M, Marengo M, Olivieri C, et al. (2018) Perfluorocarbon solutions limit tubular epithelial cell injury and promote CD133 ${ }^{+}$kidney progenitor differentiation: potential use in renal assist devices for sepsis-associated acute kidney injury and multiple organ failure. Nephrol Dial Transplant 33:1110-1121.

Cardenas ASB, Samuel PP, and Olson JS (2017) 2017 Military supplement: current challenges in the development of acellular hemoglobin oxygen carriers by protein engineering. Shock DOI: 10.1097/SHK.0000000000001053 [published ahead of print].

Castro CI and Briceno JC (2010) Perfluorocarbon-based oxygen carriers: review of products and trials. Artif Organs 34:622-634.

Centis V and Vermette P (2009) Enhancing oxygen solubility using hemoglobin- and perfluorocarbon-based carriers. Front Biosci 14:665-688.

Chang TM (1988) Red blood cell substitutes: microencapsulated hemoglobin and cross-linked hemoglobin including pyridoxylated polyhemoglobin \& conjugated hemoglobin. Biomater Artif Cells Artif Organs 16:11-29.

Chang TM (2012) From artificial red blood cells, oxygen carriers, and oxygen therapeutics to artificial cells, nanomedicine, and beyond. Artif Cells Blood Substit Immobil Biotechnol 40:197-199.

Chen JY, Scerbo M, and Kramer G (2009) A review of blood substitutes: examining the history, clinical trial results, and ethics of hemoglobin-based oxygen carriers. Clinics (São Paulo Brazil) 64:803-813.

Davis JM, El-Haj N, Shah NN, Schwartz G, Block M, Wall J, Tidswell M, and DiNino E (2018) Use of the blood substitute HBOC-201 in critically ill patients during sickle crisis: a three-case series. Transfusion 58:132-137.

Doherty DH, Doyle MP, Curry SR, Vali RJ, Fattor TJ, Olson JS, and Lemon DD (1998) Rate of reaction with nitric oxide determines the hypertensive effect of cellfree hemoglobin. Nat Biotechnol 16:672-676.

Dubé GP, Pitman AN, and Mackenzie CF (2017) Relative efficacies of HBOC-201 and polyheme to increase oxygen transport compared to blood and crystalloids. "2017 military supplement". Shock DOI: 10.1097/SHK.0000000000001058 [published ahead of print].

Elmer J, Alam HB, and Wilcox SR (2012) Hemoglobin-based oxygen carriers for hemorrhagic shock. Resuscitation 83:285-292.

Epperla N, Strouse C, VanSandt AM, and Foy P (2016) Difficult to swallow: warm autoimmune hemolytic anemia in a Jehovah's Witness treated with hemoglobin concentrate complicated by achalasia. Transfusion 56:1801-1806.

Eriksson NL and Bülow L (2017) A green alternative for the development of HBOCs, in XVI ISBS Int Symposium Blood Substitutes \& Oxygen Therapeutics, V ISNS Nanomedicine Conference (Chang T ed), Faculty of McGill University, Montreal, Canada. Abstract band page 35.

ErythroMer. (2017) Package insert. Kalocyte Inc., St. Louis, MO.

Fabian TC (2011) Perfluorocarbons. J Trauma 70 (Suppl 5):S42-S44.

Faithfull NS (1992) Oxygen delivery from fluorocarbon emulsions-aspects of convective and diffusive transport. Biomaterials, artificial cells, and immobilization biotechnology : official journal of the International Society for Artificial Cells and Immobilization Biotechnology 1992;20: 797-804.

Ferenz KB (2019) Artificial oxygen carriers, in Membrane Applications in the Artificial Organs and Tissue Engineering (Basile A, Piemonte V, Charcosset C, and Annesini M eds) Elsevier, Amsterdam, The Netherlands.

Furrer MA, Fellmann A, Schneider MP, Thalmann GN, Burkhard FC, and Wuethrich PY (2018) Impact of packed red blood cells and fresh frozen plasma given during radical cystectomy and urinary diversion on cancerrelated outcome and survival: an observational cohort study. Eur Urol Focus 4 : 916-923.

Giarratana MC, Marie T, Darghouth D, and Douay L (2013) Biological validation of bio-engineered red blood cell productions. Blood Cells Mol Dis 50:69-79. 
Giarratana MC, Rouard H, Dumont A, Kiger L, Safeukui I, Le Pennec PY, François S, Trugnan G, Peyrard T, Marie T, et al. (2011) Proof of principle for transfusion of in vitro-generated red blood cells. Blood 118:5071-5079.

Glorion M, Polard V, Favereau F, Hauet T, Zal F, Fadel E, and Sage E (2018) Prevention of ischemia-reperfusion lung injury during static cold preservation by supplementation of standard preservation solution with HEMO2life ${ }^{\circledR}$ in pig lung transplantation model. Artif Cells Nanomed Biotechnol 46:1773-1780.

Gomez MF, Aljure O, Ciancio G, and Lynn M (2017) Hemoglobin-based oxygen carrier rescues double-transplant patient from life-threatening anemia. Am J Transplant 17:1941-1944.

Greenwalt TJ (2005) Antibodies, antigens, and anticoagulants: a historical review of a lifetime in transfusion medicine-the Landsteiner Lecture 2004. Transfusion 45:1531-1539.

Gupta AS (2017) 2017 Military supplement: hemoglobin-based oxygen carriers: current state-of-the-art and novel molecules. Shock DOI: 10.1097/SHK.0000000000001009 [published ahead of print].

Haruki R, Kimura T, Iwasaki H, Yamada K, Kamiyama I, Kohno M, Taguchi K, Nagao S, Maruyama T, Otagiri M, et al. (2015) Safety evaluation of hemoglobinalbumin cluster "HemoAct" as a red blood cell substitute. Sci Rep 5:12778.

Hemopure. (2014) Package insert. Hemoglobin Oxygen Therapeutics LLC, South Africa.

Hosgood SA and Nicholson ML (2010) The role of perfluorocarbon in organ preservation. Transplantation 89:1169-1175.

Jahr JS, Akha AS, and Holtby RJ (2012) Crosslinked, polymerized, and PEGconjugated hemoglobin-based oxygen carriers: clinical safety and efficacy of recent and current products. Curr Drug Discov Technol 9:158-165.

Jahr JS, Moallempour M, and Lim JC (2008) HBOC-201, hemoglobin glutamer-250 (bovine), Hemopure ${ }^{\circledR}$ (Biopure Corporation). Expert Opin Biol Ther 8:1425-1433.

Jani VP, Jelvani A, Moges S, Nacharaju P, Roche C, Dantsker D, Palmer A, Friedman JM, and Cabrales P (2017) Polyethylene glycol camouflaged earthworm hemoglobin. PLoS One 12:e170041.

Jung $\mathrm{H}$ and Choi I (2014) Thioredoxin-interacting protein, hematopoietic stem cells, and hematopoiesis. Curr Opin Hematol 21:265-270.

Keipert P (2006) Oxygent, a perfluorochemical-based oxygen therapeutic for surgical patients, in Blood Substitutes (Winslow RM ed) pp 312-323, Elsevier, London.

Keipert PE (2017) Hemoglobin-based oxygen carrier (HBOC) development in trauma: previous regulatory challenges, lessons learned, and a path forward. Adv Exp Med Biol 977:343-350.

Keipert PE, Faithfull NS, Roth DJ, Bradley JD, Batra S, Jochelson P, and Flaim KE (1996) Supporting tissue oxygenation during acute surgical bleeding using a perfluorochemical-based oxygen carrier. Adv Exp Med Biol 388:603-609.

Keipert PE; MP4CO-SCD-105 Study Investigators (2016) Clinical evaluation of MP4CO: a phase $1 \mathrm{~b}$ escalating-dose, safety and tolerability study in stable Adult patients with sickle cell disease. Adv Exp Med Biol 923:23-29.

Kitagishi H, Mao Q, Kitamura N, and Kita T (2017) HemoCD as a totally synthetic artificial oxygen carrier: improvements in the synthesis and $\mathrm{O}_{2} / \mathrm{CO}$ discrimination. Artif Organs 41:372-380.

Kohno M, Ikeda T, Hashimoto R, Izumi Y, Watanabe M, Horinouchi H, Sakai H, Kobayashi K, and Iwazaki M (2017) Acute 40\% exchange-transfusion with hemoglobin-vesicles in a mouse pneumonectomy model. PLoS One 12:e0178724.

Kuzmiak-Glancy S, Covian R, Femnou AN, Glancy B, Jaimes R III, Wengrowski AM, Garrott K, French SA, Balaban RS, and Kay MW (2018) Cardiac performance is limited by oxygen delivery to the mitochondria in the crystalloid-perfused working heart. Am J Physiol Heart Circ Physiol 314:H704-H715.

Kuznetsova IN (2003) Drug synthesis methods and manufacturing technologies of perfluorocarbon emulsions: stability in vitro and in vivo (a review). Pharm Chem $J$ 37:20-25.

Latson GW (2017) 2017 Military supplement to shock journal Perftoran ${ }^{\mathrm{TM}}$ (Vidaphor $^{\mathrm{TM}}$ )_ introduction to western medicine. Shock DOI: 10.1097/SHK.0000000000001063 [published ahead of print].

Le Pape F, Cosnuau-Kemmat L, Richard G, Dubrana F, Férec C, Zal F, Leize E, and Delépine P (2017) HEMOXCell, a new oxygen carrier usable as an additive for mesenchymal stem cell culture in platelet lysate-supplemented media. Artif Organs 41:359-371.

Le Pape F, Richard G, Porchet E, Sourice S, Dubrana F, Férec C, Polard V, Pace R Weiss P, Zal F, et al. (2018) Adhesion, proliferation and osteogenic differentiation of human MSCs cultured under perfusion with a marine oxygen carrier on an allogenic bone substitute. Artif Cells Nanomed Biotechnol 46:95-107.

Liu J. personal communication on Oxygent. In: Ferenz KB, ed. on XVI ISBS Int. Symposium Blood Substitutes \& Oxygen Therapeutics/ V ISNS Nanomedicine Conference, Nov. 13th-15th 2017, Montreal, 2017.

Lowe KC (2003) Engineering blood: synthetic substitutes from fluorinated compounds. J Tissue Eng 9:389-399.

Lowe KC (2006) Blood Substitutes: from Chemistry to Clinic. J Mater Chem 16:4189-4196.

Lundy JB, Lewis CJ, Cancio LC, and Cap AP (2014) Experience with the use of Hemopure in the care of a massively burned adult. Int J Burns Trauma 4:45-48.

Mackenzie CF, Dubé GP, Pitman A, and Zafirelis M (2017) Users guide to pitfalls and lessons learned about HBOC-201 during clinical trials, expanded access, and clinical use in 1,701 patients. Shock DOI: DOI: $10.1097 /$ SHK.0000000000001038 [published ahead of print].

Mackenzie CF, Pitman AN, Hodgson RE, Sussman MJ, Levien LJ, Jahr JS, and Greenburg AG (2015) Are hemoglobin-based oxygen carriers being withheld because of regulatory requirement for equivalence to packed red blood cells? Am $J$ Ther 22:e115-e121.

Mallet V, Dutheil D, Polard V, Rousselot M, Leize E, Hauet T, Goujon JM, and Zal F (2014) Dose-ranging study of the performance of the natural oxygen transporter HEMO2 Life in organ preservation. Artif Organs 38:691-701.

Mason KA, Withers HR, and Steckel RJ (1985) Acute effects of a perfluorochemical oxygen carrier on normal tissues of the mouse. Radiat Res 104:387-394.
McCarthy MR, Vandegriff KD, and Winslow RM (2001) The role of facilitated diffusion in oxygen transport by cell-free hemoglobins: implications for the design of hemoglobin-based oxygen carriers. Biophys Chem 92:103-117.

McConachie SM, Almadrahi Z, Wahby KA, and Wilhelm SM (2018) Pharmacotherapy in acutely anemic Jehovah's Witnesses: an evidence-based review. Ann Pharmac other 52:910-919.

Meier J, Filipescu D, Kozek-Langenecker S, Llau Pitarch J, Mallett S, Martus P, and Matot I; ETPOS collaborators (2016) Intraoperative transfusion practices in Europe. Br J Anaesth 116:255-261.

Meng F, Kassa T, Jana S, Wood F, Zhang X, Jia Y, D'Agnillo F, and Alayash AI (2018) Comprehensive biochemical and biophysical characterization of hemoglobin-based oxygen carrier therapeutics: all HBOCs are not created equally. Bioconjug Chem 29:1560-1575.

Mer M, Hodgson E, Wallis L, Jacobson B, Levien L, Snyman J, Sussman MJ, James M, van Gelder A, Allgaier R, et al. (2016) Hemoglobin glutamer-250 (bovine) in South Africa: consensus usage guidelines from clinician experts who have treated patients. Transfusion 56:2631-2636

Meybohm P, Herrmann E, Steinbicker AU, Wittmann M, Gruenewald M, Fischer D, Baumgarten G, Renner J, Van Aken HK, Weber CF, et al.; PBM-Study Collaborators (2016) Patient blood management is associated with a substantial reduction of red blood cell utilization and safe for patient's outcome: a prospective, multicenter cohort study with a noninferiority design. Ann Surg 264:203-211.

Natanson C, Kern SJ, Lurie P, Banks SM, and Wolfe SM (2008) Cell-free hemoglobin-based blood substitutes and risk of myocardial infarction and death: a meta-analysis. JAMA 299:2304-2312.

Neya S, Yonetani T, and Kawaguchi AT (2014) Usefulness of myoglobin containing cobalt heme cofactor in designing a myoglobin-based artificial oxygen carrier. Artif Organs 38:715-719.

Njoku M, St Peter D, and Mackenzie CF (2015) Haemoglobin-based oxygen carriers: indications and future applications. Br J Hosp Med (Lond) 76:78-83.

Okumura S, Uemura T, Zhao X, Masano Y, Tsuruyama T, Fujimoto Y, Iida T, Yagi S, Bezinover D, Spiess B, et al. (2017) Liver graft preservation using perfluorocarbon improves the outcomes of simulated donation after cardiac death liver transplantation in rats. Liver Transpl 23:1171-1185.

Olaussen A, Bade-Boon J, Fitzgerald MC, and Mitra B (2018) Management of injured patients who were Jehovah's Witnesses, where blood transfusion may not be an option: a retrospective review. Vox Sang 113:283-289.

Olson JS, Foley EW, Rogge C, Tsai AL, Doyle MP, and Lemon DD (2004) No scavenging and the hypertensive effect of hemoglobin-based blood substitutes. Free Radic Biol Med 36:685-697.

Ortiz D, Barros M, Yan S, and Cabrales P (2014) Resuscitation from hemorrhagic shock using polymerized hemoglobin compared to blood. Am J Emerg Med 32:248-255.

Oxygen Biotherapeutics Announces Halt of Oxycyte Phase IIb Traumatic Brain Injury Trial. (2014) Press release September 11, 2014. Tenax Therapeutics, Morrisville, NC. https://www.businesswire.com/news/home/20140911006403/en/ Oxygen-Biotherapeutics-Announces-Halt-Oxycyte-Phase-IIb.

Pan D, Rogers S, Misra S, Vulugundam G, Gazdzinski L, Tsui A, Mistry N, Said A Spinella P, Hare G, et al. (2016) Erythromer (EM), a nanoscale bio-synthetic artificial red cell: proof of concept and in vivo efficacy results. Blood 128:1027.

Posluszny JA Jr and Napolitano LM (2014) How do we treat life-threatening anemia in a Jehovah's Witness patient? Transfusion 54:3026-3034.

Posluszny JA and Napolitano LM (2016) Hemoglobin-based oxygen carrier for traumatic hemorrhagic shock treatment in a Jehovah's Witness. Arch Trauma Res 5:e30610.

Ratanasopa K, Cedervall T, and Bülow L (2016) Possibilities of using fetal hemoglobin as a platform for producing hemoglobin-based oxygen carriers (HBOCs). Adv Exp Med Biol 876:445-453.

Resar LM, Wick EC, Almasri TN, Dackiw EA, Ness PM, and Frank SM (2016) Bloodless medicine: current strategies and emerging treatment paradigms. Transfusion 56:2637-2647.

Riess JG (2001) Oxygen carriers ("blood substitutes")—raison d'etre, chemistry, and some physiology. Chem Rev 101:2797-2920.

Riess JG (2005) Understanding the fundamentals of perfluorocarbons and perfluorocarbon emulsions relevant to in vivo oxygen delivery. Artif Cells Blood Substit Immobil Biotechnol 33:47-63.

Rousselot M, Delpy E, Drieu La Rochelle C, Lagente V, Pirow R, Rees JF, Hagege A Le Guen D, Hourdez S, and Zal F (2006) Arenicola marina extracellular hemoglobin: a new promising blood substitute. Biotechnol $J$ 1:333-345.

Roux FA, Saï P, and Deschamps JY (2007) Xenotransfusions, past and present. Xenotransplantation 14:208-216.

Sakai H (2017) Overview of Potential Clinical Applications of Hemoglobin Vesicles $(\mathrm{HbV})$ as Artificial Red Cells, Evidenced by Preclinical Studies of the Academic Research Consortium. J Funct Biomater 8.

Schiedlmeier B, Santos AC, Ribeiro A, Moncaut N, Lesinski D, Auer H, Kornacker K, Ostertag W, Baum C, Mallo M, et al. (2007) HOXB4's road map to stem cell expansion. Proc Natl Acad Sci USA 104:16952-16957.

Scurtu VF, Moț AC, and Silaghi-Dumitrescu R (2013) Protein-based blood substitutes: recent attempts at controlling pro-oxidant reactivity with and beyond hemoglobin. Pharmaceuticals (Basel) 6:867-880.

Seekell RP, Lock AT, Peng Y, Cole AR, Perry DA, Kheir JN, and Polizzotti BD (2016) Oxygen delivery using engineered microparticles. Proc Natl Acad Sci USA 113: $12380-12385$

Shen L, Qu R, Shi H, Huang F, An Y, and Shi L (2016) A biocompatible cobaltporphyrin-based complex micelle constructed via supramolecular assembly for oxygen transfer. Biomater Sci 4:857-862.

Simoni J (2017) Artificial oxygen carriers: exactly how close are we to an ultimate product? Artif Organs 41:316-318.

Simons M, Gretton S, Silkstone GGA, Rajagopal BS, Allen-Baume V, Syrett N, Shaik T, Leiva-Eriksson N, Ronda L, Mozzarelli A, et al. (2018) Comparison of 
the oxidative reactivity of recombinant fetal and adult human hemoglobin: implications for the design of hemoglobin-based oxygen carriers. Biosci Rep 38: BSR20180370.

Spahn DR (2018) Artificial oxygen carriers: a new future? Crit Care 22:46

Spahn DR and Keipert PE (2017) Shock 2017 military supplement an overview of two human trials of perfluorocarbon emulsions in non-cardiac surgery. Shock DOI: 10.1097/SHK.0000000000000986 [published ahead of print].

Spahn DR, van Brempt R, Theilmeier G, Reibold JP, Welte M, Heinzerling H, Birck KM, Keipert PE, Messmer K, Heinzerling H, et al.; European Perflubron Emulsion Study Group (1999) Perflubron emulsion delays blood transfusions in orthopedic surgery. Anesthesiology 91:1195-1208.

Spahn DR, Waschke KF, Standl T, Motsch J, Van Huynegem L, Welte M, Gombotz H Coriat P, Verkh L, Faithfull S, et al.; European Perflubron Emulsion in NonCardiac Surgery Study Group (2002) Use of perflubron emulsion to decrease allogeneic blood transfusion in high-blood-loss non-cardiac surgery: results of a European phase 3 study. Anesthesiology 97:1338-1349.

Spiess BD (2009) Perfluorocarbon emulsions as a promising technology: a review of tissue and vascular gas dynamics. J Appl Physiol 106:1444-1452.

Sun C, Wang Y, Yao HS, and Hu ZQ (2015) Allogeneic blood transfusion and the prognosis of gastric cancer patients: systematic review and meta-analysis. Int $J$ Surg 13:102-110.

Taguchi K, Yamasaki K, Maruyama T, and Otagiri M (2017) Comparison of the pharmacokinetic properties of hemoglobin-based oxygen carriers. J Funct Biomater 8:E11.

Takahashi K and Yamanaka S (2006) Induction of pluripotent stem cells from mouse embryonic and adult fibroblast cultures by defined factors. Cell 126:663-676.

Tang J, Cui X, Caranasos TG, Hensley MT, Vandergriff AC, Hartanto Y, Shen D, Zhang H, Zhang J, and Cheng K (2017) Heart repair using nanogel-encapsulated human cardiac stem cells in mice and pigs with myocardial infarction. ACS Nano 11:9738-9749.

Taverne YJ, de Wijs-Meijler D, Te Lintel Hekkert M, Moon-Massat PF, Dube GP, Duncker DJ, and Merkus D (2017) Normalization of hemoglobin-based oxygen carrier-201 induced vasoconstriction: targeting nitric oxide and endothelin. J Appl Physiol (1985) 122:1227-1237.

Teh ES, Zal F, Polard V, Menasché P, and Chambers DJ (2017) $\mathrm{HEMO}_{2}$ life as a protective additive to Celsior solution for static storage of donor hearts prior to transplantation. Artif Cells Nanomed Biotechnol 45:717-722.

Terraneo L, Bianciardi P, Malavalli A, Mkrtchyan G, Spann SN, Lohman J, Samaja M, and Vandegriff KD (2017) Hemoglobin extravasation in the brain of rats exchangetransfused with hemoglobin-based oxygen carriers. Artif Cells Nanomed Biotechnol 45:710-716.

Tissot JDBM, Bardyn M, Sonego G, Abonnenc M, and Prudent M (2017) The storage lesions: from past to future. Transfus Clin Biol 24:277-284.

Toma VA, Farcas AD, Roman I, Sevastre B, Hathazi D, Scurtu F, Damian G, and Silaghi-Dumitrescu R (2018) In vivo evaluation of hemerythrin-based oxygen carriers: similarities with hemoglobin-based counterparts. Int J Biol Macromol 107:1422-1427.

Tsai AG, Cabrales P, Young MA, Winslow RM, and Intaglietta M (2015) Effect of oxygenated polyethylene glycol decorated hemoglobin on microvascular diameter and functional capillary density in the transgenic mouse model of sickle cell anemia. Artif Cells Nanomed Biotechnol 43:10-17.

Van Hemelrijck J, Levien L.J, Veeckman L, Pitman A, Zafirelis Z, and Standl T (2014) A safety and efficacy evaluation of hemoglobin-based oxygen carrier HBOC-201 in a randomized, multicenter red blood cell controlled trial in noncardiac surgery patients. Anesth Analg 119:766-776.

van Veen T and Hunt JA (2015) Tissue engineering red blood cells: a therapeutic. $J$ Tissue Eng Regen Med 9:760-770.

Varnado CL, Mollan TL, Birukou I, Smith BJZ, Henderson DP, and Olson JS (2013) Development of recombinant hemoglobin-based oxygen carriers. Antioxid Redox Signal 18:2314-2328.

Velásquez JF and Cata JP (2015) Transfusions of blood products and cancer outcomes. Rev Esp Anestesiol Reanim 62:461-467.

Vidaphor. (2017) Package insert. Fluoro2Therapeutics, Boca Raton, FL.

Winslow RM (2006) Current status of oxygen carriers ('blood substitutes'): 2006. Vox Sang 91:102-110.

Wollocko H, Anvery S, Wollocko J, Harrington JM, and Harrington JP (2017) Zero-link polymerized hemoglobin $\left(\mathrm{OxyVita}{ }^{\circledR} \mathrm{Hb}\right)$ stabilizes the heme environment: potential for lowering vascular oxidative stress. Artif Cells Nanomed Biotechnol 45:701-709.

Wrobeln A, Laudien J, Gross-Heitfeld C, Linders J, Mayer C, Wilde B, Knoll T, Naglav D, Kirsch M, and Ferenz KB (2017a) Albumin-derived perfluorocarbon-based artificial oxygen carriers: a physico-chemical characterization and first in vivo evaluation of biocompatibility. Eur J Pharm Biopharm 115:52-64.

Wrobeln A, Schlüter KD, Linders J, Zähres M, Mayer C, Kirsch M, and Ferenz KB (2017b) Functionality of albumin-derived perfluorocarbon-based artificial oxygen carriers in the Langendorff-heart. Artif Cells Nanomed Biotechnol 45:723-730.

Yu J, Vodyanik MA, Smuga-Otto K, Antosiewicz-Bourget J, Frane JL, Tian S, Nie J, Jonsdottir GA, Ruotti V, Stewart R, et al. (2007) Induced pluripotent stem cell lines derived from human somatic cells. Science 318:1917-1920.

Zhang $\mathrm{H}$ and Barralet JE (2017) Mimicking oxygen delivery and waste removal functions of blood. Adv Drug Deliv Rev 122:84-104.

Zimmerman D, DiIusto M, Dienes J, Abdulmalik O, and Elmer JJ (2017) Direct comparison of oligochaete erythrocruorins as potential blood substitutes. Bioeng Transl Med 2:212-221.

Address correspondence to: Dr. Katja B. Ferenz, Institute of Physiology, University Hospital Essen, Hufelandstrasse 55, 45122 Essen, Germany. E-mail: katja.ferenz@uk-essen.de 